\title{
Analysis of organometallics dispersed polymer composite irradiated with oxygen ions
}

\author{
N L SINGH*, ANJUM QURESHI, A K RAKSHIT ${ }^{\dagger}$ and D K AVASTHI ${ }^{\dagger \dagger}$ \\ Physics Department, ${ }^{\dagger}$ Chemistry Department, M.S. University of Baroda, Vadodara 390 002, India \\ ${ }^{\dagger \dagger}$ Nuclear Science Centre, Aruna Asaf Ali Marg, New Delhi 110 067, India
}

\begin{abstract}
Thin films of polymethyl methacrylate (PMMA) were synthesized. Ferric oxalate was dispersed in PMMA films. These films were irradiated with $80 \mathrm{MeV} \mathrm{O}^{6+}$ ions at a fluence of $1 \times 10^{11}$ ions $/ \mathrm{cm}^{2}$. The radiation induced changes in electrical conductivity, Mössbauer parameter, microhardness and surface roughness were investigated. It is observed that hardness and electrical conductivity of the film increases with the concentration of dispersed ferric oxalate and also with the fluence. It indicates that ion beam irradiation promotes (i) the metal to polymer bonding and (ii) convert the polymeric structure into hydrogen depleted carbon network. Thus irradiation makes the polymer harder and more conductive. Before irradiation, no Mössbauer absorption was observed. The irradiated sample showed Mössbauer absorption, which seems to indicate that there is significant interaction between the metal ion and polymer matrix. Atomic force microscopy shows that the average roughness $\left(R_{\mathrm{a}}\right)$ of the irradiated film is lower than the unirradiated one.
\end{abstract}

Keywords. Polymethyl methacrylate (PMMA); ion irradiation; dielectric properties; microhardness; Mössbauer spectroscopy; AFM.

\section{Introduction}

In recent years, there is an increasing interest in polymer matrix composites prepared by mixing two or more constituents to make up some disadvantages in single material (Chen et al 2000; Etienne et al 2000; Pan et al 2000). For instance by combining different fillers with polymer, polymer composites with special physical properties applied in areas such as capacitor (Bai et al 2000; Dang et al 2002, 2003), can be fabricated. To prepare the composites with excellent dielectric property, therefore, the effective utilization of filled polymers depends strongly on loading fillers being homogeneous throughout polymer (Xiao et al 2001) and effective microstructure in the composites. Furthermore, interfaces among the different phases in the composites play also an important role on deciding the dielectric property. During the last few years much work has been done to study different aspects of metal/polymer interface formation using various microscopic and surface sensitive techniques. It is known that good adhesion between polymer and metal is crucial to device performance and reliability by the use of ion beam (Wang et al 2004; Zaporojtchenko et al 2000). The chemical changes brought about by ion beam in polymers underline that the physical modifications are limited to a few basic processes: gas evolution, cross linking and degradation. The chemical changes are more dramatic in polymers because of the macromolecular structure of these materials. The kind of changes, which predominate, depends on the polymer type

*Author for correspondence (singhnl_msu@yahoo.com) and radiation dosage. The ion irradiated polymers exhibited improved oxidation resistance and increased electrical conductivity. In this work, we show a new way to insert metal atoms into a polymer matrix. Organometallic compound (ferric oxalate) is in complex form and will give more functional groups after ion beam irradiation compared to inorganic fillers. There is a possibility to form oxides, hydroxides and other compounds by irradiation of organometallic dispersed polymer films. The ferric oxalate dispersed PMMA films were irradiated with $80 \mathrm{MeV} \mathrm{O}^{6+}$ ions at a fluence of $1 \times 10^{11} \mathrm{ions} / \mathrm{cm}^{2}$, and radiation induced changes in mechanical (microhardness), electrical properties, Mössbauer spectroscopy and surface roughness of the PMMA/organometallics composite films were investigated.

\section{Experimental}

As an organometallic compound, we used ferric oxalate. It was formed by taking $6 \cdot 24 \mathrm{~g}$ of oxalic acid and $5 \cdot 24 \mathrm{~g}$ of ferric chloride with ethanol as a solvent in a round bottom flask, and it was refluxed for $4 \mathrm{~h}$ at $60^{\circ} \mathrm{C}$. The excess of ethanol was then distilled out and the substance was dried at $75^{\circ} \mathrm{C}$ for $3 \mathrm{~h}$ in an oven. PMMA was prepared by solution polymerization method. In this method, benzoyl peroxide (BPO, $0.8 \mathrm{~g}$; an initiator for polymerization) was dissolved in freshly inhibitor free MMA ( $80 \mathrm{ml}$ methyl methacrylate) monomer and ethyl acetate as a solvent $(80 \mathrm{ml})$ in a round bottom flask and the solution was then refluxed for $5 \mathrm{~h}$ at $80^{\circ} \mathrm{C}$ temperature in hot water bath. The resulting solution was then precipitated out in another beaker con- 
taining methanol $(100 \mathrm{ml})$. The PMMA, precipitated out in methanol, was dried at room temperature for $2 \mathrm{~h}$. The polymerized PMMA and ferric oxalate compound of $10 \%$ was dissolved using acetone and the solutions were mixed and stirred thoroughly for about an hour and poured on clean glass trough. The solvent was evaporated at room temperature $\left(25 \pm 1^{\circ} \mathrm{C}\right)$ to get thin films (thickness, $\sim 50 \mu \mathrm{m}$ ) of dispersed PMMA with $10 \%$ concentration of ferric oxalate compound. The films were used for irradiation. Films were irradiated with $80 \mathrm{MeV} \mathrm{O}^{6+}$ ions at a fluence of $1 \times 10^{11}$ ions $/ \mathrm{cm}^{2}$ from the pelletron at the Nuclear Science Centre, New Delhi. A Carl Zeiss microscope and its accessories were used to investigate Vickers microhardness and surface morphology of pristine and irradiated surfaces were obtained using an atomic force microscopy (AFM) in the contact mode. AC electrical properties of all samples were measured in the frequency range $0 \cdot 1-100 \mathrm{kHz}$ at room temperature using variable frequency LCR meter (General Radio, USA; model-1689). The conductivity was calculated using the relation

$$
\sigma=t / R A\left(\Omega^{-1} \mathrm{~cm}^{-1}\right)
$$

where $R$ is the resistance measured, $A$ the cross-sectional area of the electrode and $t$ the thickness of the polymeric film. Mössbauer spectra were recorded at room temperature using $\mathrm{Co}^{57}(\mathrm{Rh})$ source in the constant acceleration mode. The line width of the spectrometer was $0.27 \mathrm{~mm} / \mathrm{s}$. Spectra were recorded before and after irradiation.

\section{Results and discussion}

\subsection{AC electrical frequency response}

AC electrical measurement was performed for pristine and irradiated samples. Figure 1 shows the variation of $\log$ resistivity with $\log$ of frequency for the pristine and irradiated samples of pure PMMA and at $10 \%$ ferric oxalate concentration dispersed PMMA films. It is seen that the resistivity decreases rapidly in proportion to $f^{-1}$. It is also observed that resistivity decreases with increasing concentration of dispersed ferric oxalate compound in pure PMMA. For irradiated samples at a fluence of $1 \times 10^{11}$ ions/ $\mathrm{cm}^{2}$, further decrease in resistivity is observed. The decrease in resistivity or increase in conductivity with ferric oxalate concentration for pristine samples may be attributed to the conductive phase formed by dispersed organometallic compound in polymer matrix. It is known that electrical conductivity of such composites depends on the type and concentration of the dispersed compound (Abu-Abdeen et al 2002; Mamunya et al 2002). As a result, the resistivity of dispersed films decreases on dispersion of ferric oxalate compound in the polymer matrix. It is also observed that after irradiation the resistivity of dispersed organometallic compound decreases. It is expected to promote metal-topolymer adhesion and convert the polymeric structure to a hydrogen depleted carbon network. It is this carbon network that is believed to make the polymers more conductive (Wang et al 2004).

Figure 2 shows the plot of dielectric constant vs log frequency for pristine and irradiated samples of pure PMMA and ferric oxalate dispersed PMMA films. As evident from the graph, the dielectric constant remains almost constant up to $100 \mathrm{kHz}$. At these frequencies, the motion of the free charge carriers is constant and hence there is no change in dielectric constant. It is also revealed that dielectric constant increases for ferric oxalate dispersed for pristine and irradiated samples.

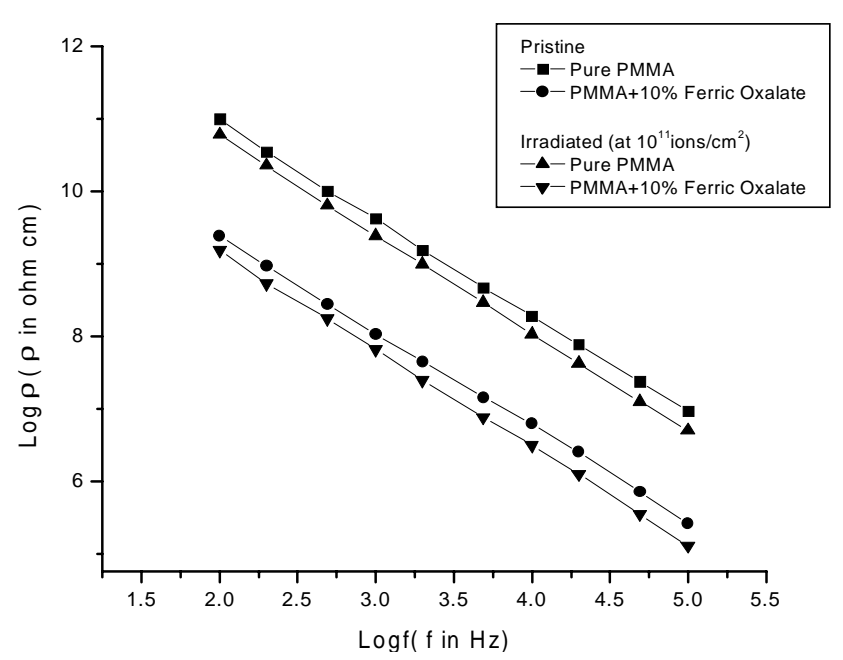

Figure 1. Plot of log resistivity vs log frequency for pristine and irradiated pure and $10 \%$ dispersed ferric oxalate in PMMA films.

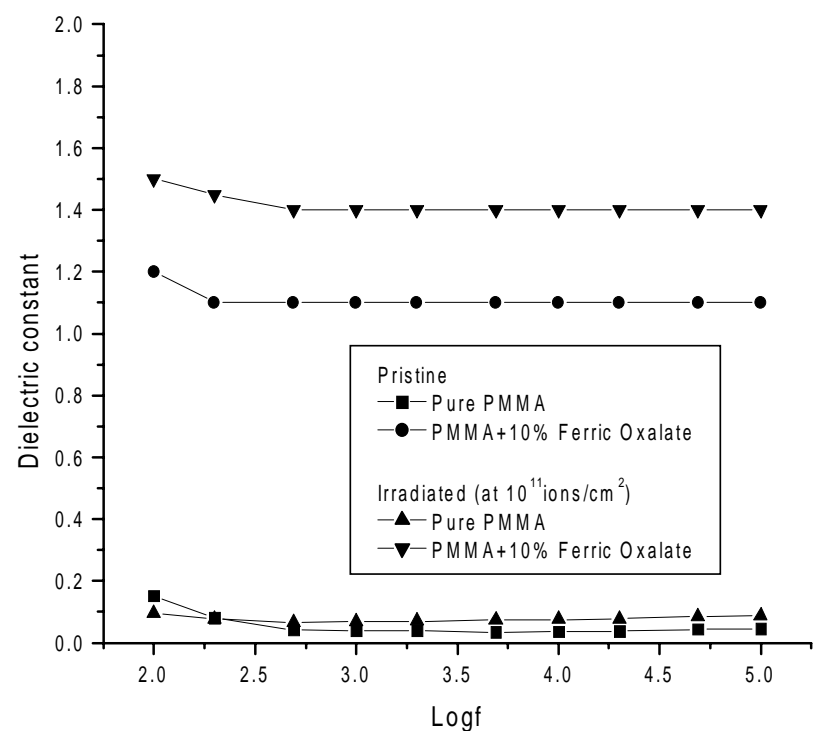

Figure 2. Plot of dielectric constant vs $\log$ frequency for pristine and irradiated pure and $10 \%$ dispersed ferric oxalate in PMMA films. 


\subsection{Microhardness}

Figure 3 shows the plot of the Vickers microhardness $\left(H_{\mathrm{v}}\right)$ vs applied load $(P)$ for pristine and irradiated films of pure PMMA, and dispersed ferric oxalate compound of $10 \%$ in PMMA films. The microhardness indentations were carried out on the surface of the pristine and irradiated films at room temperature under different applied loads from 50-1000 $\mathrm{mN}$ and at a constant loading time of $30 \mathrm{~s}$.

It has been observed that microhardness $\left(H_{\mathrm{v}}\right)$ value increases with the load up to $100 \mathrm{mN}$ and then decreases and become saturated beyond the load of $400 \mathrm{mN}$. Hardness can be defined as resistance to indenter penetration, or as the average pressure under the indenter, calculated as the applied load divided by the projected area of contact incorporating the plastic component of displacement. The hardness is known to be influenced by surface effects. Particularly at low penetration depths, the strain hardening modifies the true hardness of the material. At higher loads, beyond $400 \mathrm{mN}$, the interior of the bulk specimen is devoid of surface effects. Hence, the hardness value at higher loads represents the true value of the bulk and it is consequently independent of the load. It is found that hardness increases for ferric oxalate dispersed PMMA films. It may be due to the improvement in bonding properties (Bowyer et al 1972). The hardness also increases on irradiation of the samples. This may be attributed to hydrogen depleted carbon network which makes the polymer harder (Wang et al 2004).

\subsection{Mössbauer studies}

Mössbauer spectra were recorded for the samples before and after irradiation. The least square fitted values of unirradiated sample are listed in table 1 and spectrum is shown in figure 4 . The fitted values indicate quadrupole splitting (QS) of $\sim 0.45 \mathrm{~mm} / \mathrm{s}$ which corresponds to the $\mathrm{Fe}-\mathrm{C}$ complex as reported earlier (Somayajulu et al 2001). Thus in unirradiated sample there is only $\mathrm{Fe}-\mathrm{C}$ nonmagnetic complexes formed. It is possible that $\mathrm{Fe}$ ions were either residing in the voids between the chains or got attached to the $-\mathrm{COOCH}_{3}$ group in the side chain without cross linking before irradiation. PMMA is known to undergo chain scissioning even at low (keV) ion energies. Therefore, high energy of the ion transferred energy per atom to the polymer chains makes scissioning more intense which may result in the amorphization of the sample. In the present case, after high energy irradiation of ferric oxalate dispersed PMMA films, it is expected that there is a possibility of the formation of cluster of Fe with oxygen, giving rise to magnetic interaction. However, the

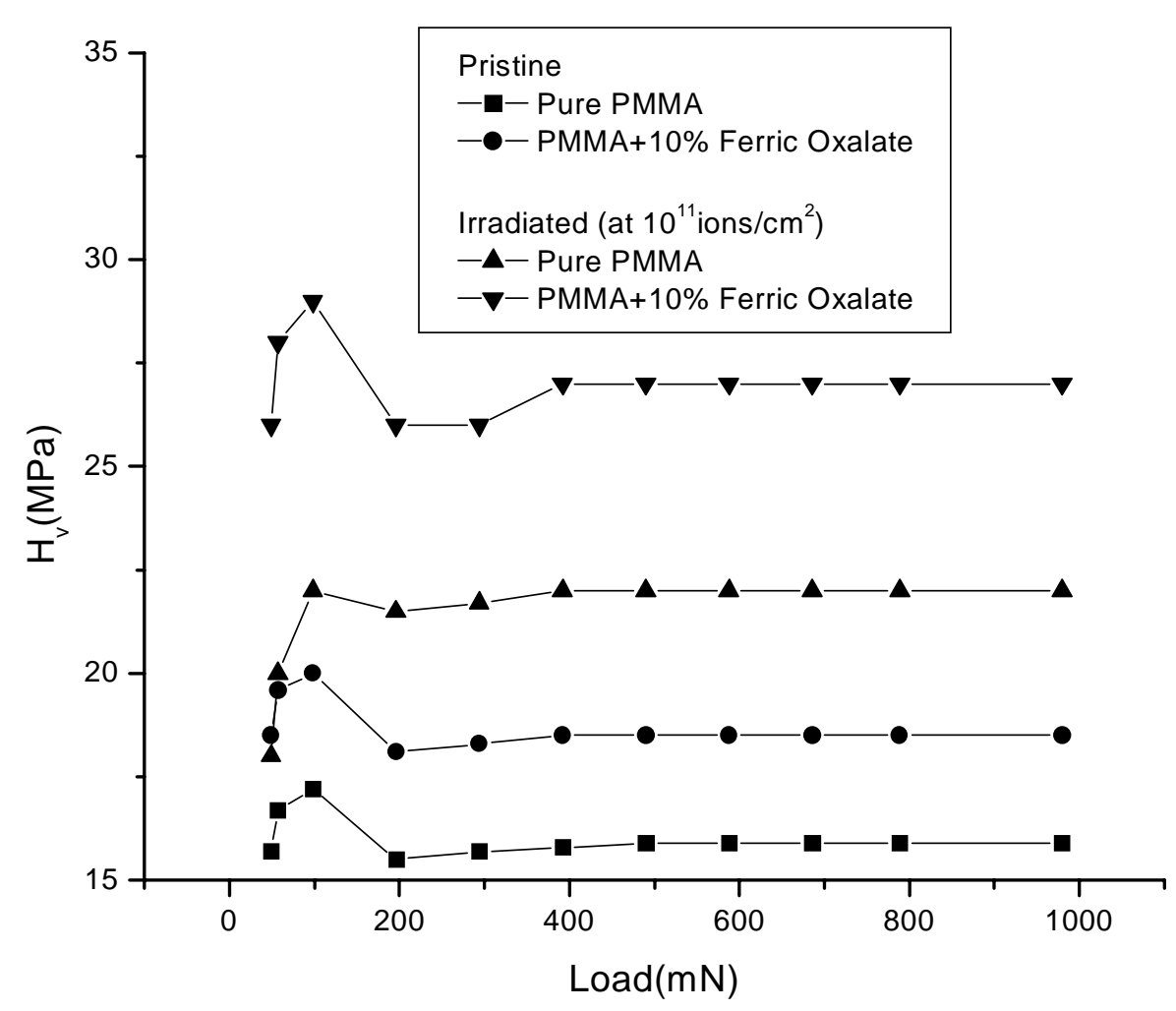

Figure 3. Plot of hardness $\left(H_{\mathrm{v}}\right)$ vs applied load $(P)$ for pristine and irradiated pure and $10 \%$ dispersed ferric oxalate in PMMA films. 


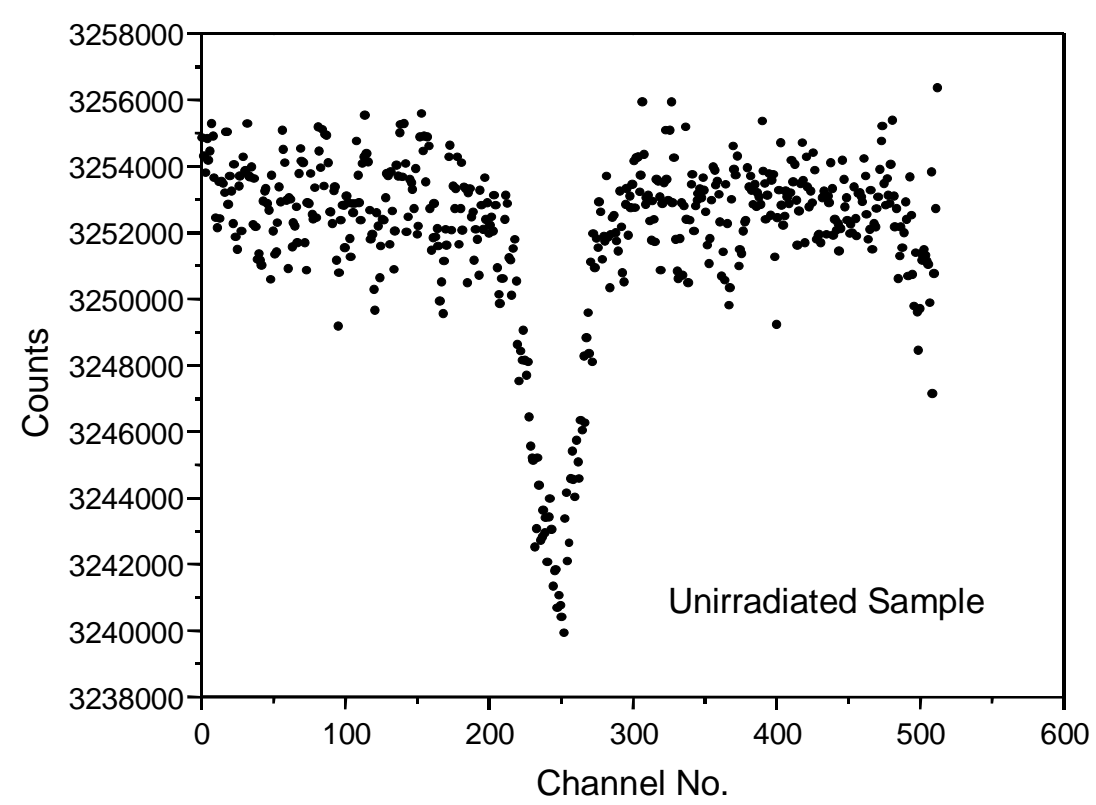

Figure 4. Mössbauer spectra of dispersed ferric oxalate (10\%) in PMMA film (pristine).
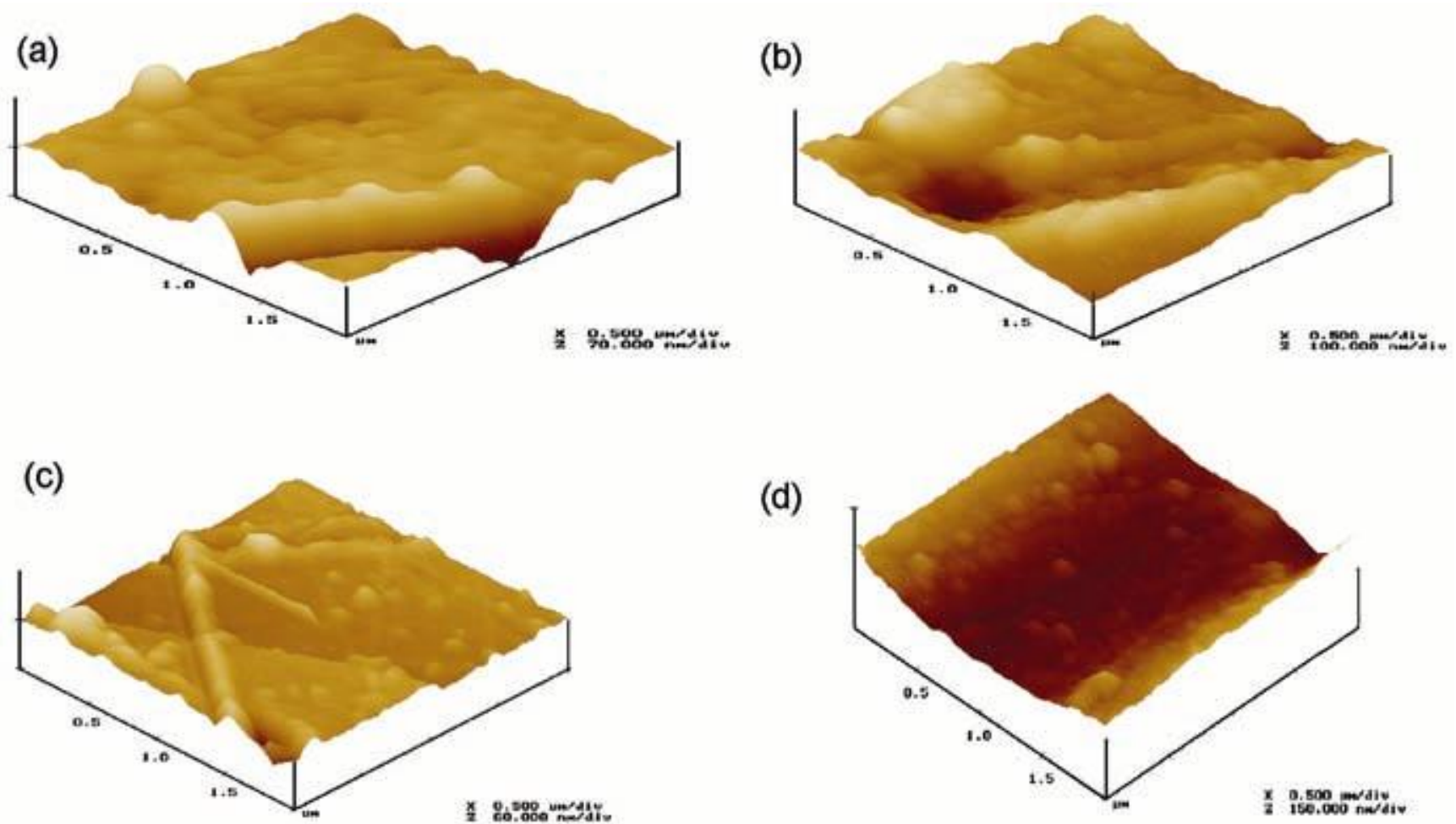

(d)

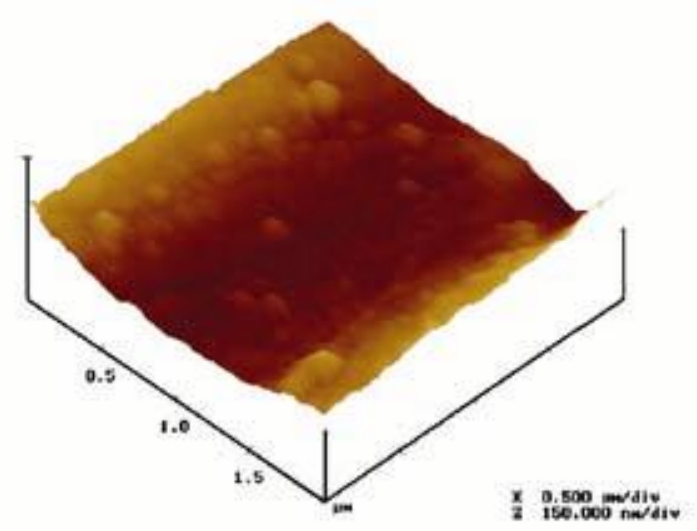

Figure 5. (a) AFM image of pure PMMA film (pristine), (b) AFM image of dispersed ferric oxalate (10\%) in PMMA film (pristine), (c) AFM image of pure PMMA film (irradiated) and (d) AFM image of dispersed ferric oxalate (10\%) in PMMA film (irradiated).

irradiated sample showed magnetic site with field values of $\sim 510 \mathrm{kOe}$. This indicates that there is a formation of $\mathrm{Fe}-\mathrm{O}$ (could be $\mathrm{Fe}_{2} \mathrm{O}_{3}$ phase) complex into the polymer matrix, by consequent breakage of $\mathrm{Fe}-\mathrm{C}$ bonds which were observed in unirradiated sample. From Mössbauer spectra, the value of QS and isomer shift (IS) for the irradiated samples showed that $\mathrm{Fe}$ is in the state $3+$ or more. The spectra indicate the formation of magnetic sextet $(\mathrm{Fe}-\mathrm{O})$ with a doublet $(\mathrm{Fe}-\mathrm{C})$. The absorption \% was low due to less quantity of irradiated material. 
Table 1. Mössbauer parameter of dispersed ferric oxalate (10\%) in PMMA film.

\begin{tabular}{lcc}
\hline $\begin{array}{l}\text { Quadrupole splitting } \\
(\mathrm{mm} / \mathrm{s})\end{array}$ & $\begin{array}{c}\text { Isomer shift } \\
(\mathrm{mm} / \mathrm{s})\end{array}$ & Fractional area \\
\hline 0.45 & -0.29 & 1 \\
\hline
\end{tabular}

\subsection{Atomic force microscopy}

The surface morphology of pristine and irradiated films of pure PMMA, and dispersed ferric oxalate compound of $10 \%$ in PMMA was measured by AFM on $2 \times 2 \mu \mathrm{m}^{2}$ area are shown in figure 5. Each AFM image is analysed in terms of surface average roughness $\left(R_{\mathrm{a}}\right)$. The roughness values are $13 \mathrm{~nm}$ and $21 \mathrm{~nm}$ for pristine and $6 \mathrm{~nm}$ and $19 \cdot 2 \mathrm{~nm}$ for irradiated (at the fluences of $10^{11}$ ions $/ \mathrm{cm}^{2}$ ) samples, respectively. It is found that roughness increases for dispersed ferric oxalate polymeric film. The increase in roughness may be due to the increase of density and size of metal particles on the surfaces of PMMA films (Yan et al 2004). It is also observed that after irradiation the roughness of the surface decreases and the surface becomes significantly smoother. This relative smoothness is probably due to the sputtering effects (Qureshi et al 2006).

\section{Conclusions}

Ion irradiation has been shown to significantly enhance electrical, Mössbauer absorption and microhardness of organometallic compound dispersed PMMA films. It may be attributed to (i) metal to polymer adhesion and (ii) conversion of the polymeric structure to hydrogen depleted carbon network. Thus irradiation makes the polymer harder and more conductive. Mössbauer studies indicate that there is a formation of $\mathrm{Fe}-\mathrm{O}$ (could be $\mathrm{Fe}_{2} \mathrm{O}_{3}$ phase) complex into the polymer matrix due to irradiation. The surface roughness increases for dispersed ferric oxalate
PMMA film and decreases on irradiation as observed from AFM studies.

\section{Acknowledgements}

Authors are thankful to the Nuclear Science Centre (NSC), New Delhi, for providing irradiation facility and IUCDAFE, Indore, for providing AFM facility. The financial support given by NSC, New Delhi, is gratefully acknowledged.

\section{References}

Abu-Abdeen M, Nasr G M, Osman H M and Abound A I 2002 Egypt. J. Sol. 25275

Bai Y, Cheng Z Y, Bharti V, Xu H S and Zhang Q M 2000 Appl. Phys. Lett. 783804

Bowyer W H and Bader M G 1972 J. Mater. Sci. 71315

Chen W M, Yuan Y and Yan L F 2000 Mater. Res. Bull. 35807

Dang Z M, Shen Y and Nan C W 2002 Appl. Phys. Lett. 81 4814

Dang Z M, Lin Y H and Nan C W 2003 Adv. Mater. 151625

Etienne S, Stochil C and Bessede J L 2000 J. Alloys Comp. 310 368

Mamunya Ye P, Davydenko V V, Pissis P and Lebedev E V 2002 Eur. Polym. J. 381887

Pan T, Huang J P and Li Z Y 2000 Appl. Phys. B301 190

Qureshi A, Singh N L, Rakshit A K, Singh F and Ganesan V 2006 Nucl. Instrum. \& Meth. B244 235

Somayajulu D R S, Murthy C N, Awasthi D K, Patel N V and Sarkar M 2001 Bull. Mater. Sci. 24397

Wang Y Q, Curry M, Tavenner E, Dobson N and Giedd R E 2004 Nucl. Instrum. \& Meth. B219-220 798

Xiao P, Xiao M and Gong K C 2001 Polymer 424813

Yan X, Xu T, Xu S, Wang S and Yang S 2004 Nanotechnology 151759

Zaporojtchenko V, Strunskus T, Behnke K, von Bechtolsheim C, Keine M and Faupel F 2000 J. Adhesion Sci. Technol. 14 467 